\title{
Save the Nymphs!
}

\section{Gerard Zwang*}

Association Against Child Uterine, France

*Corresponding author: Gérard Zwang, md 44 Chemin des sarments F 34980 Saint Clément de rivière, France.

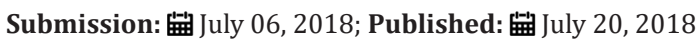

\section{Opinion}

The sex of women, the vulva, is the most despised, the most insulted, the most censured, and the most mutilated human organ. Its representation is an absolute taboo of Western statuary. It does not appear on any artwork decorating town halls, public places, public squares, and show rooms. While the virile organs are scrupulously figured, exposed to all, including children. At least the West can boast of no mutilating the sexual organ of little girls, a crime of which the savages (although represented at the UN an UNESCO) who perform clitoral excision are guilty.

However, for the past twenty years or so, professionals without scruples practice what they call "cosmetic surgery", " surgery of the intimate", pride themselves of doing a favor to women by amputating more or less of their labia minora-the nymphs, declared too long, annoying and in aesthetic. How we came to consider a mutilating practice reminiscent of the package made for millenia by excisers who usually sacrifice the nymphs with the clitoris as an embellishment of the "modern woman"? Ignorant of the real anatomical configuration of the vulva, the practice of what is now called "labioplasty" was instituted in three steps.
Anatomical ignorance is due in the fact that women almost never see the sex of their congeners. The adult vulva never appears in everyday life; we need the intimacy of cohabitation between women showing them naked, or care provided in the family for one woman to see the sex of another. Rare eventuality. A woman may have seen in her life only her own vulva-still they have to use a mirror-and that of her little daughter(s). Whereas a man will have seen the sex of a dozen of his feminine companions during his lifetime-western average. Only health professionals (doctors, lab assistants, nurses) know how others are made, which dispenses them from questioning about their own aspect. The usual Anatomy Treatises themselves add to the poor knowledge of vulvar configuration. They show the organ largely wide, spread to see the intimate details, by falling to show it closed, as it is in everyday life. They omit too to show the diversity of the nymphs ${ }^{1}$. I have not seen in any of French Treatises (Rouvière, Testut et Jacob, Bourgery) the representation of the female hypogastric region, whit sex seen from the front (Figure 1). We can see the triangular hair, and the head the clitoral hood and nymphs coming out the vulvae cleft of about 4 of 5 women.

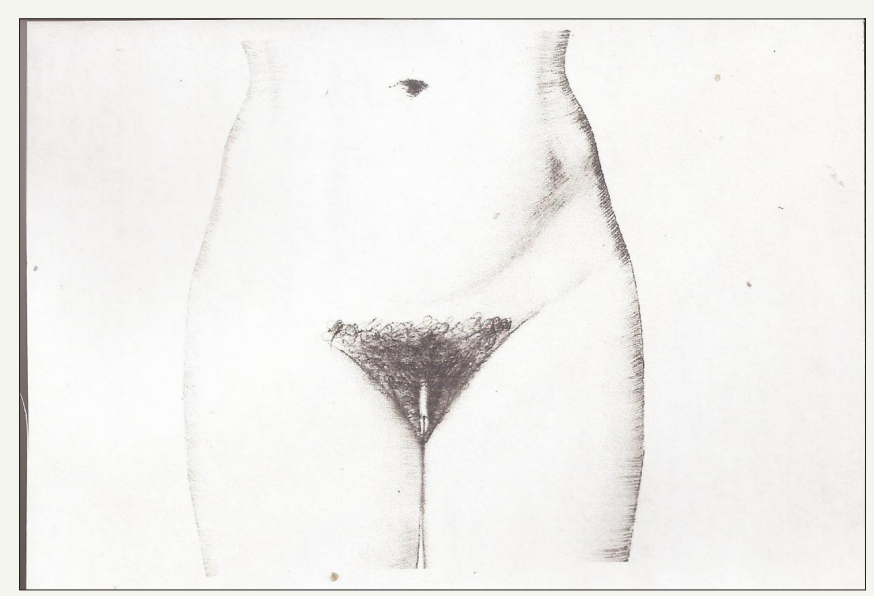

Figure 1: The female hypogastric region, document from: Gérard Zwang: "Le Sexe de la femme»

\footnotetext{
${ }^{1}$ Only two anatomists show this diversity. In France Felix Jayle: La Gynécologie. In the USA R.L Dickinson: Atlas of human sex anatomy.
} 
The first time of the aggression goes back to the spread of socalled brazilian swimsuit. Unlike to the usual clothes, whose lower limit goes to inguinal folds to hide the pubic hair, their lower part is more or less indented on the sides, discovering more or less the hairiness. The practice is then instituted, to shave these incongruous hairs. Those who wear the razor on their pubic hair take the bad habit "get made her swimingsuit", a "care" priced in Beauty salons, disfiguring the index triangle of femininity, deputized for a "subway ticket", or the Hitler's mustache. They obey without balking to the ukases of designers, who evidently prefer beautiful rangy young men instead "banal" adult women.

The second step was to extend shaving to all sexual hair, or even to perform permanent hair removal, to be "tranquil". Like the porno-stars. So is born the "tuftless" fashion. These hairless women thus consider themselves "very clean" even though they resemble to very wise and obedient little girl, as are the women subject to
Islam law. Moreover the mowing of the labia majora lets appear ostensibly what is usually partially hidden by the hairs. As a result, many of these women are worried. They see "skins" coming out of their sex they have not seen anywhere before, not even in painting. Instead of asking their sister or friends, they will usually seek advice from their doctor.

A good practitioner reassures them, informing them of the reality. The small lips normally come out of the vulva cleft; they are very variable in tint and in size (Figure 2 shows four usual types: short, $1-2 \mathrm{~cm}$, medium triangular or semi-lunar, $3 \mathrm{~cm}$, aliform, like the wings of a butterfly, $4 \mathrm{~cm}$ and more). It is a very personal attribute: two women do not have identical nymphs. It is even a privilege of the human species. No other mammalian female possesses these delicate ornaments. It would better to reverence them than amputate them.

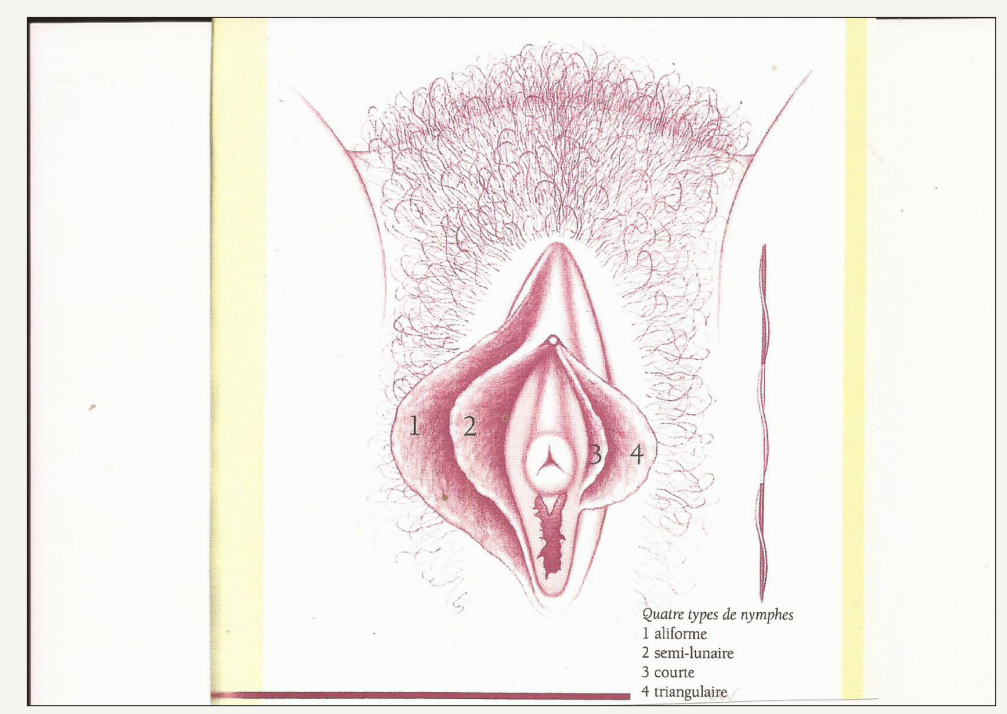

Figure 2: Four usual models of nymphs, document from Gérard Zwang: "Atlas du sexe de la femme"

Alas "cosmetic" surgeons listen to these worries and offer them their services... generously paid. The cut off "all that exceeds", so that their sex looks like a nice split apricot. They will legitimate their damages by incriminating the false embarrassments that these women would suffer. But their nymphs have never embarrassed women when urinating, copulating, or giving birth. The Hottentot women, who used to pull their labia minora could not marry if they had not managed to make a nice "apron" that would protrude about 3-5 centimeters from their vulvae slit. Have the "surgeons of intimate" ever deal with such an hypertrophy? I have never seen one in forty years of urogenital surgery. Those who epilate their tuft and are their nymphs planed have paid dearly to two prejudices:

\section{Infantilization}

The adult woman, nubile, has a distinctive triangular pubic fleece, which makes their femininity recognized and arouses the male desire. Glabrous, they look like a little girl, that has not the worries and the responsibilities of an adult's sexual life.

\section{Standardization}

Their sacrificed hairiness was distinguished by color, implantation more or less side, type (frizzy, smooth, curly and so on). Their nymphs reduced to a small slot became stereotyped. Gladys's sex looks the same as that of others passed to the shaper, Audrey, Emily, Julia, theirs sisters, theirs cousins... Is it a progress of the feminine condition?

To comply with fashion porn movies stars, as well, tend to get stunted nymphs, therefore giving disastrous sexual information, in particular to suggestible teenagers. The claim of mutilation will only be extinguished when the artists shall represent the sex of woman as it is, with realistic hairs, clitoral hood and nymphs, when the anatomists shall teach the great diversity of these labia minora. Is it for tomorrow?

As far as I'm concerned, I was of course solicited by women unhappy of their anatomy. I began by telling them their nymphs were very nice, and that they were part of their personality. Then 
I suggested that they come back for a future consultation. A blouse on their shoulders they played trainees and in three hours could see the sex of at least ten other women. So they saw that the others had also small lips coming out the vulvae cleft. Have I convinced all of them to give up suffering the outrages of labioplasty? At least I had accomplished my duty as a surgeon, which is to operate the diseased organs and do not attack the normal body of normal women. (c) Creative Commons Attribution 4.0 International License

For possible submissions Click Here

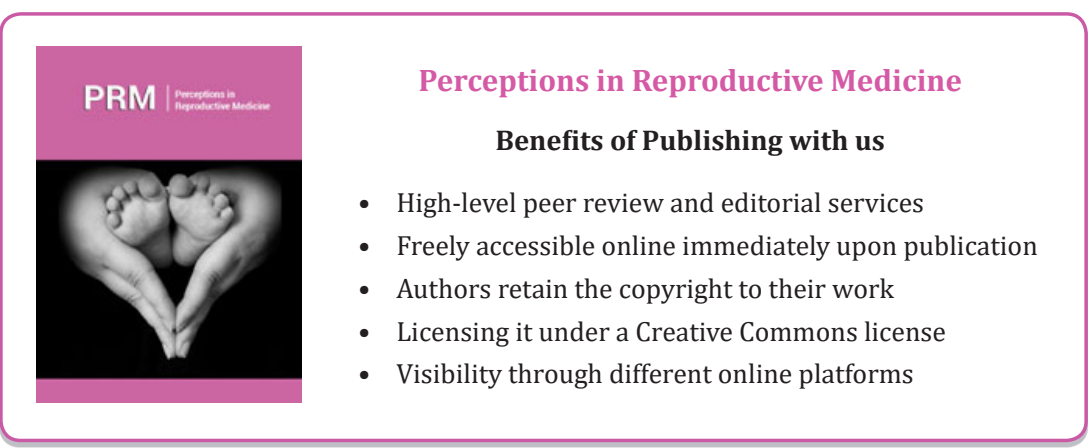

